\title{
SWALLOW HABI-TECH : \\ PENANGKARAN DAN GALERI WALET DI KARST CIAMPEA, BOGOR, INDONESIA
}

\author{
Maria Stefani ${ }^{1)}$, Alvin Hadiwono ${ }^{2)}$ \\ 1)Program Studi S1 Arsitektur, Fakultas Teknik, Universitas Tarumanagara, stmariastefani@gmail.com \\ 2) Program Studi S1 Arsitektur, Fakultas Teknik, Universitas Tarumanagara, alvinh@ft.untar.ac.id
}

Masuk: 03-07-2021, revisi: 15-08-2021, diterima untuk diterbitkan: 23-10-2021

\begin{abstract}
Abstrak
Pemanasan global merupakan permasalahan umum yang terjadi di seluruh belahan dunia yang memicu terjadinya perubahan iklim yang cukup signifikan seperti kenaikan suhu, perubahan kelembaban, bencana alam, dan dapat menyebabkan kepunahan flora dan fauna, salah satunya burung walet di Karst Ciampea, yang sudah mengalami kerusakan sehingga tidak layak huni. Selain itu, eksploitasi gua kapur oleh manusia menyebabkan walet merasa tidak nyaman dan diperlukannya habitat buatan. Tujuannya agar kebutuhan walet akan habitat pengganti terpenuhi sehingga ekosistem Karst Ciampea tidak terganggu. Bentuk arsitektur yang dihasilkan berupa penangkaran berbasis teknologi yang mengambil walet sebagai subjek utama proyek. Metode yang digunakan berawal dari fenomena dan urgensi walet yang terjadi di kawasan Karst Ciampea. Kemudian dianalisa dan dihasilkan ide berupa penangkaran. Tetapi, tidak hanya berbatas pada penangkaran, tersedia juga ruang interaksi untuk menusia yang berupa galeri-galeri walet, sehingga pengunjung dapat memandang kehidupan walet. Bentuk bangunan keseluruhan didasarkan pada studi analisa bentuk gerakan terbang walet, sehingga bangunan mengadaptasi banyak bentuk lengkungan yang leluasa sesuai dengan aktivitas keseharian walet. Untuk metode penangkaran, diawali dengan menggunakan teknik adaptasi terlebih dahulu, yaitu dengan menangkarkan burung seriti yang mengasuh telur walet yang diambil dari gua-gua kapur Karst Ciampea. Selain metode dalam perancangan, penggunaan teknologi pada material bangunan terutama penangkaran dan galeri juga banyak menggunakan bahan alami seperti kayu dan dinding bata ekspos yang bersifat alami. Sehingga, untuk menampilkan sisi 'melampaui ekologi', tidak hanya terbatas pada ekologi dalam penggunaan material, tetapi terdapat ruang interaksi yang tidak langsung antara manusia dengan walet berfungsi untuk melawan sikap antroposentris manusia, sekaligus membantu manusia untuk turut merasakan kehidupan walet dalam suatu bangunan arsitektur.
\end{abstract}

Kata kunci: galeri; habitat; penangkaran; teknologi; walet putih.

\begin{abstract}
Global warming is a common problem that occurs in all parts of the world that triggers significant climate changes such as temperature increases, humidity changes, natural disasters, and can cause the extinction of flora and fauna, one of which is the swallow in Ciampea Karst, which has been damaged so that uninhabitable. In addition, the exploitation of limestone caves by humans causes swallows to feel uncomfortable and the need for artificial habitats. The goal is that the swallow's need for replacement habitat is fulfilled so that the Ciampea Karst ecosystem is not disturbed. The resulting architectural form is a technology-based captivity that takes swallows as the main subject of the project. The method used begins with the phenomenon and urgency of swallows that occur in Ciampea Karst area. Then analyzed and generated ideas in the form of captivity. However, it is not only limited to captivity, there is also an interaction space for humans in the form of swallow galleries, so that visitors can see the swallow's life. The overall shape of the building is based on an analysis study of the shape of the swallow's flying movement, so that the building adapts many forms of arches that are flexible in accordance with the swallow's daily activities. For the breeding method, it begins by using adaptation techniques first, namely by breeding the seriti bird that takes
\end{abstract}


care of swallow eggs taken from the limestone caves of the Ciampea Karst. In addition to methods in design, the use of technology in building materials, especially in captivity and galleries, also uses natural materials such as natural exposed wood and brick walls. So, to show the side 'beyond ecology', it is not only limited to ecology in the use of materials, but there is an indirect interaction space between humans and swallows that functions to fight against human anthropocentric attitudes, while helping humans to feel the swallow's life in an architectural building.

\section{Keywords: captivity; gallery; habitat; technology; white swallow.}

\section{PENDAHULUAN}

\section{Latar Belakang}

Pemanasan global (global warming) merupakan sebuah fenomena yang menjadi salah satu faktor besar yang terjadi di seluruh dunia sehingga menyebabkan ketidakseimbangan ekosistem di bumi, berupa terjadinya peningkatan suhu berlebih pada lapisan atmosfer, laut, dan darat. Perubahan iklim tersebut sangat berpengaruh pada berbagai aspek kehidupan dalam sebuah rangkaian ekosistem yang terdiri dari lingkungan abiotik, biotik dan alam itu sendiri. Contohnya, burung walet yang mengalami kepunahan karena sulit beradaptasi dengan iklim yang terlalu panas.

Burung walet merupakan salah satu spesies hewan endemik yang biasa ditemukan di daerah lembab, seperti gua, hutan, sawah dan juga pantai. Butuh ruang luas bagi burung walet untuk bermanuver dengan kecepatan tinggi. Burung ini juga tipe hewan yang dapat mencari makanan sendiri. Namun, karena kakinya kecil, burung ini tidak dapat hinggap di dahan pohon atau pun di tempat berhinggap yang menyerupai kabel listrik dan sejenisnya. Maka dari itu, walet lebih suka tinggal di gua dan ruang tertutup lainnya di mana ia bisa membuat sarangnya sendiri dari air liurnya. Namun, karena alasan tergesernya habitat dan juga dampak perubahan iklim yang cukup ekstrem, burung walet yang tidak bisa tinggal di daerah yang tidak lembab membutuhkan habitat pengganti. Sehingga, untuk membuat sarang, burung walet memerlukan suatu tempat yang lembab dengan suhu yang pas agar air liur tidak cepat mengering dan dapat menghasilkan sarang yang nyaman untuk ditinggali dan juga berkualitas tinggi bagi manusia yang memanennya.

Manusia terus-menerus mencoba membuat habitat pengganti, terlebih untuk hewan endemik demi berbagai keperluan manusia. Misalnya, Karst Ciampea di daerah Bogor mulai terkikis karena manusia dengan segala keserakahannya, terus-menerus mengeksploitasi alam tanpa berpikir panjang. Akibatnya banyak burung walet yang tadinya bertinggal di sana, menjadi kehilangan tempat dan makanan sehingga kesulitan menemukan habitat baru. Pada akhirnya, banyak koloni burung walet mulai menetap di bangunan-bangunan manusia yang gelap, lembab, dan yang tidak berpenghuni. Habitat walet pun kini sudah cukup berubah. Selain itu, habitat buatan manusia yang memang tidak sempurna seperti habitat asli burung walet, dapat menimbulkan ketidakseimbangan ekosistem. Adanya ancaman burung hantu dalam memangsa burung walet karena ukuran-ukuran lubang bangunan tidak sesuai. Juga buruknya penataan ruang dan sikap asal-asalan manusia yang sembarangan membangun bangunan walet di tengah permukiman penduduk dapat menyebabkan ancaman wabah flu burung. Sehingga, diperlukan suatu penangkaran burung walet untuk mencegah kepunahan walet. Maka dari itu, arsitektur berperan penting dalam penataan dan pendukung ekosistem burung walet untuk terus bertahan meskipun masih terus-menerus banyak mengalami over-eksploitasi, khususnya di daerah Karst Ciampea, Kabupaten Bogor. Sehingga, penangkaran berbasis teknologi diharapkan dapat menjadi jawaban atas permasalahan yang terjadi dalam meminimalisir dan mempertahankan spesies walet agar ekosistem karst tetap seimbang. 


\section{Rumusan Permasalahan}

Perlunya peranan arsitektur dalam menanggapi konsep "Melampaui Ekologi” untuk membantu menyeimbangkan kembali kebutuhan habitat burung walet yang terancam punah di daerah Karst Ciampea yang mulai rusak. Program penangkaran berbasis teknologi serta ruang spasial yang menyadarkan manusia akan sifat antroposentrisme juga diperlukan untuk menunjang aktivitas burung walet dan manusia dalam suatu simbiosis mutualisme.

\section{Tujuan}

Menguraikan konsep "Melampaui Ekologi Menuju Kehidupan untuk Kebaikan dan Kehidupan" dalam arsitektur berkelanjutan untuk membantu menjaga populasi burung walet. Kemudian juga menciptakan suatu penangkaran walet yang menunjang walet sebagai subjek utama proyek dan meminimalisir dampak eksploitasi manusia terhadap jumlah populasi burung walet.

\section{KAJIAN LITERATUR}

\section{Ekologi}

Ekologi berasal dari kata Bahasa Yunani yaitu Oikos yang artinya rumah dan Logos yang artinya ilmu pengetahuan. Sehingga, adalah suatu pemahaman atau ilmu tentang hubungan timbalbalik antar semua makhluk hidup yang ada di bumi dengan alam atau lingkungannya.

\section{Ekologi Dalam}

"Ekologi Dalam menuntut adanya suatu kebaharuan dalam ekosentris atau etika lingkungan yang merespon makhluk hidup keseluruhan sebagai pusatnya dan bukan sebatas manusia dalam mengatasi berbagai permasalahan lingkungan." (Sessions, 1985). Paradigma inilah yang merupakan 'lawan' bagi pemahaman antroposentris. Sehingga, makhluk hidup seluruhnya tidak bergantung pada manusia, tetapi manusialah yang bergantung pada ekologi itu sendiri.

"Ecosophy merupakan kebijakan dalam sistem pengaturan atau tata kelola dalam sebuah kehidupan di bumi yang selaras dengan alam sebagai sebuah sistem dalam rangkaian ekosistem dan bukan sebatas ilmu pengetahuan tetapi juga berarti hidup selaras dengan alam dan seisinya untuk menjaga poros keseimbangan di dalam bumi." (Naess, 1989). Selain itu, pemahaman lebih lanjut tentang Ekologi Dalam ini lebih menekankan untuk keberlangsungan keberlanjutan komunitas ekologi. Sehingga, sebuah permasalahan lingkungan hanya dapat diatasi dengan terlebih dahulu membenahi pemahaman manusia itu sendiri terhadap perilaku dan cara pandangnya terhadap alam dan makhluk hidup lainnya.

\section{Melampaui Ekologi}

Melampaui ekologi seringkali dikaitkan dengan teori Ekologi Dalam (Deep Ecology) yang merupakan salah satu filosofi lingkungan dan mengandung nilai inheren dari semua makhluk hidup (biotik dan abiotik) terlepas dari kegunaan pada kondisi-kondisi tertentu untuk kebutuhan manusia dan didukung oleh teknologi yang berkembang. Melampaui dalam bahasa Indonesia sendiri artinya 'telah melalui'. "Secara umum, cukup berkaitan erat dengan ekosistem pada suatu tempat yang di dalamnya terdapat sebuah siklus biotik-abiotik-alam yang seimbang dan berkesinambungan. Keterkaitan ini lah yang melahirkan sesuatu yang disebut ekosentris yaitu sebuah etika lingkungan pada seluruh bagian ekologi." (Devall, 1985)

\section{Burung Walet}

Burung walet atau yang juga disebut Collocalia vestita dalam nama latin adalah burung jenis juga senang dan banyak hidup di daerah gua dan daerah yang dekat dengan mata air. Selain itu, 
burung walet memiliki kemampuan ekolokasi atau biosonar yang digunakan sejumlah binatang untuk mengeluarkan bunyi dan mendengar pantulan bunyi tersebut dari objek-objek di sekitar, sehingga mereka dapat melihat dalam gelap. Jenis walet tersebar menjadi 12 jenis di seluruh dunia, namun di Indonesia hanya terdapat 3 jenis yaitu :

Tabel 1. Jenis Burung Walet di Indonesia

\begin{tabular}{lc}
\hline \multicolumn{1}{c}{ Jenis Walet } & Persebarannya di Indonesia \\
\hline Collocalia fuciphaga (Walet Sarang Putih) & $\begin{array}{c}\text { Sumatera, Kalimantan, Jawa, Bali, } \\
\text { Sulawesi dan Maluku }\end{array}$ \\
\hline Collocalia maxima (Walet Sarang Hitam) & Sumatera, Kalimantan, Sulawesi \\
\hline Collocalia linchii (Seriti, Dadali, Kepinis) & endemik di pulau Jawa \\
\hline
\end{tabular}

Sumber: Mardiastuti, 2017

Burung walet sarang putih atau walet putih merupakan spesies yang paling sering dimanfaatkan oleh manusia, karena merupakan penghasil sarang putih yang memiliki banyak manfaat terutama bagi kesehatan. walet sarang putih atau Collocalia fuciphaga termasuk spesies burung dari keluarga Apodidae, dari genus Collocalia. Tubuhnya berukuran agak kecil yaitu sekitar 12 $\mathrm{cm}$. Bulunya berwarna cokelat kehitam-hitaman dan bulu bagian bawah berwarna abu-abu atau cokelat. Matanya berwarna cokelat gelap. Sedangkan paruh dan kakinya berwarna hitam. Ciri yang paling menonjol dari burung ini adalah bagian ekornya yang mempunyai belahan ke dalam.

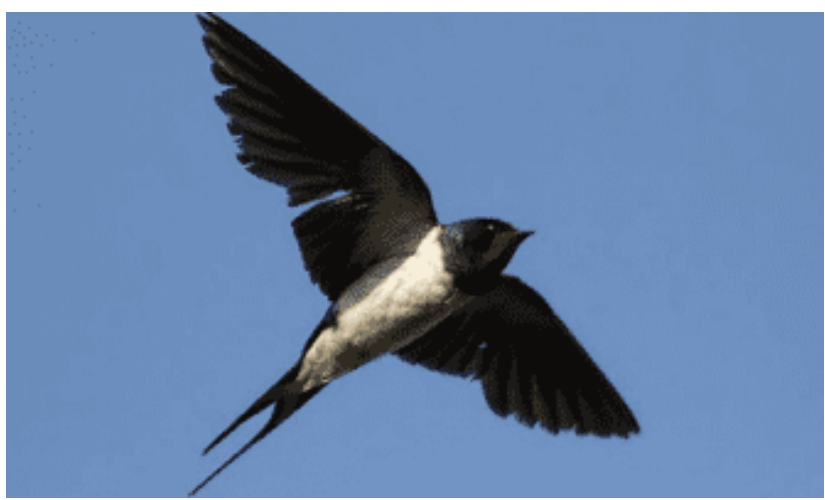

Gambar 1. Walet Sarang Putih

Sumber: Walet Putih, Burung Penyuka Kebersihan, 2021 


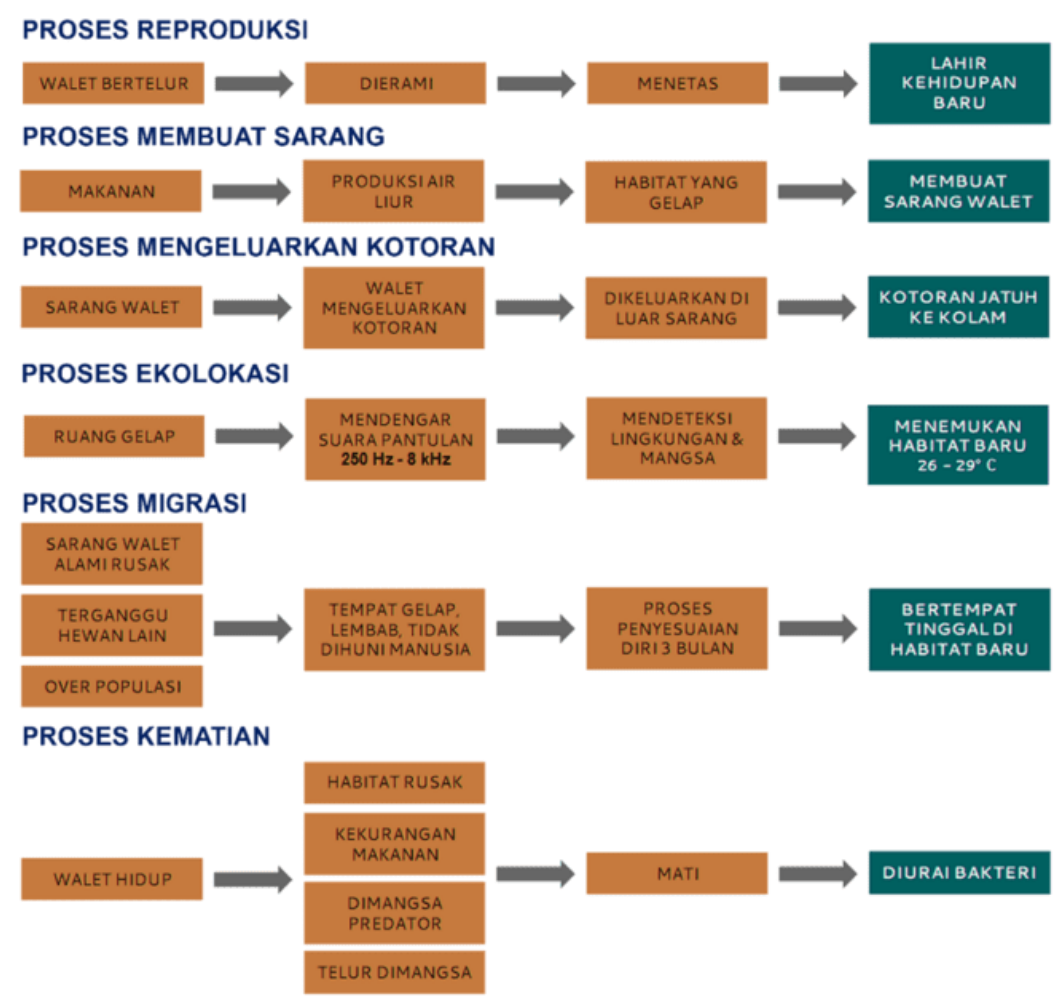

Gambar 2. Skematik Aktivitas Kehidupan Walet

Sumber: Dokumen Pribadi, 2021

Burung walet membutuhkan tempat yang tidak terkena sinar matahari dan lembab untuk menjaga kualitas air liur dalam proses pembuatan sarang burung. Gua yang cocok bagi walet adalah gua dengan suhu $26-40^{\circ} \mathrm{C}$ dan kelembaban udara sekitar $80-90 \%$. "Biasanya membuat sarang di langit-langit gua atau dengan tujuan menghindari predator dengan ketinggian sekitar 500 meter dpl." (Sumiati, 1998). Walet juga memiliki kemampuan untuk mengenali sarangnya sendiri dengan bau khasnya. Selain digunakan untuk tinggal, sarang walet juga digunakan untuk menyimpan telur-telur walet.

Burung walet dalam ekosistem Karst Ciampea beperan sebagai penyedia nutrisi bagi gua kapur, karena gua kondisinya lembab dan tidak dapat dijangkau sinar matahari. Satwa yang menjadi pemasok nutrisi bagi ekosistem gua seperti burung walet harus dilindungi karena keberadaanya menjadi awal rantai makanan dalam gua. Lalu juga sebagai makanan bagi predatornya yaitu burung hantu yang paling banyak, juga tikus, ular dan burung elang. Burung walet yang memakan serangga seperti kupu-kupu dan jangkrik juga berperan sebagai penyeimbang populasi serangga agar tetap terjaga dalam rangkaian ekosistem utamanya. Untuk manusia sendiri, burung walet memiliki manfaat yang sangat besar terutama sarang burungnya yang berkhasiat untuk kesehatan dan pangan. Selain sarangnya, kotoran dari burung walet sendiri apat dimanfaatkan di bidang pertanian sebagai pupuk alami yang sangat efektif untuk berbagai jenis tanaman. Terdapat kandungan nutrisi yang tinggi dan sangat baik bagi tanah. Misalnya, nitrogen, fosfor, kalium, kalsium, magnesium dan sulfur. 


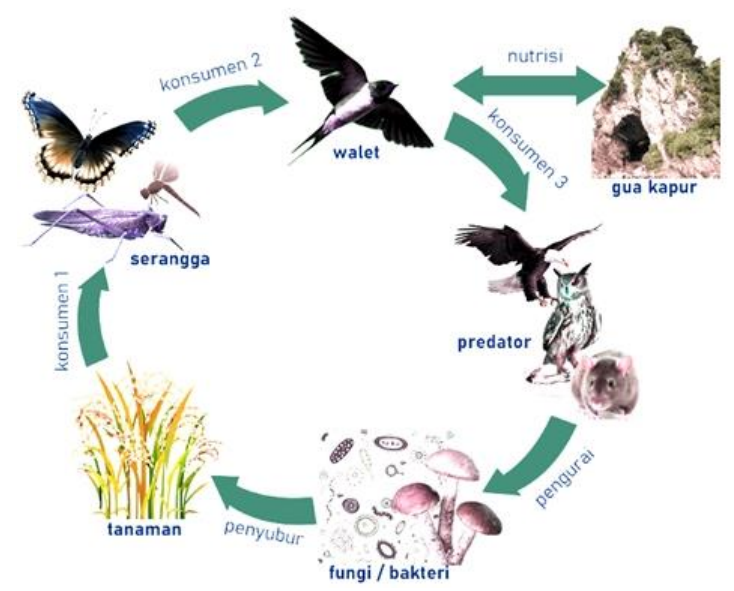

Gambar 3. Peranan Walet dalam Rantai Ekosistem Karst Sumber: Dokumen Pribadi, 2021

Apabila burung walet punah atau terganggu populasinya, maka akan menimbulkan dampak yang cukup negatif terlebih dalam rangkaian ekosistem habitat aslinya. Contohnya, timbulnya kenaikan masif jumlah serangga secara massal sehingga banyak tanaman terdampak dan juga kematian bagi hewan predator yang kesulitan mencari makanan karena populasi burung yang menurun, begitu pula dengan gua kapur yang kehilangan nutrisinya.

\section{Persepsi Spasial}

Secara umum, spasial adalah ruang atau dimensi. Kemudian persepsi spasial berhubungan kemampuan dalam membedakan komponen garis, bidang vertikal dan juga horizontal dalam suatu bangun ruang. Pemahaman tersebut dapat dialami oleh manusia dengan merasakan suasana yang ditimbulkan dari unsur-unsur komponen arsitekturnya yang berupa teksur, material, dan sebagainya. "Persepsi spasial dalam arsitektur pada akhirnya bukanlah bangunan fisik semata, tetapi makna nya terhadap kehidupan sehari-hari." (Sutanto, 2020).

\section{Penangkaran}

Penangkaran merupakan sarana untuk pembiakkan, proses, cara, perbuatan menangkarkan. Berdasarkan Peraturan Menteri Kehutanan No. P.19/ Menhut-II / 2005 tentang Penangkaran Tumbuhan dan Satwa Liar, penangkaran juga termasuk salah satu upaya perbanyakan melalui pengembangbiakan dan pembesaran tumbuhan dan satwa liar dengan tetap mempertahankan kemurnian jenisnya. Teknik menangkar dilakukan dengan cara melakukan pemeliharaan dan pembesaran spesies yang diambil dari habitat alam yang dikembangkan di dalam lingkungan terkontrol dan atau dari anakan yang diambil dari alam (ranching/rearing) dengan tetap mempertahankan jenisnya. Jadi, pembiakan satwa dan flora di luar habitat aslinya, dilakukan dengan campur tangan manusia atau biasa disebut budidaya.

\section{Tipologi Bangunan Walet}

Bangunan walet umumnya memiliki 2 tipe yaitu tipe sekat dan tipe hall. Namun tipe hall dikatakan kurang efektif dalam menangkar walet. Maka dari itu, banyak bangunan walet lebih memilih tipe sekat. "Pada bangunan walet tipe sekat, satu bangunan dibagi menjadi beberapa ruangan kecil yang masing-masing diberi sekat agar walet merasa aman dan nyaman. Terdapat Roving Room yang ukuran idealnya $3 \times 4$ meter untuk area walet bermanuver setelah memasuki lubang masuk pada gedung, dan Roving Room tidak diberi sekat apapun (void) dari lantai teratas 
hingga lantai terbawah gedung. Tujuannya agar walet lebih leluasa terbang saat memasuki Nesting Room." (Yamin \& Paimin, 2002)

\section{Galeri}

Galeri adalah sarana atau ruang untuk memamerkan benda terutama karya seni dan sejenisnya. Galeri juga dapat menjadi wadah yang menampung kegiatan komunikasi visual antara seniman ataupun kolektor seni dengan masyarakat luas melalui kegiatan pameran. (Harris, 2006)

\section{METODE}

Metode penelitian diawali dengan menggunakan metode pengumpulan data studi literatur yang berkaitan dengan habitat asli burung walet, khususnya jenis walet sarang putih. Lalu menarik isu dari fenomena tersebut dan membuat sebuah rangkaian kerangka berpikir sebagai awal mula penelitian.

$$
\text { TEORI }
$$

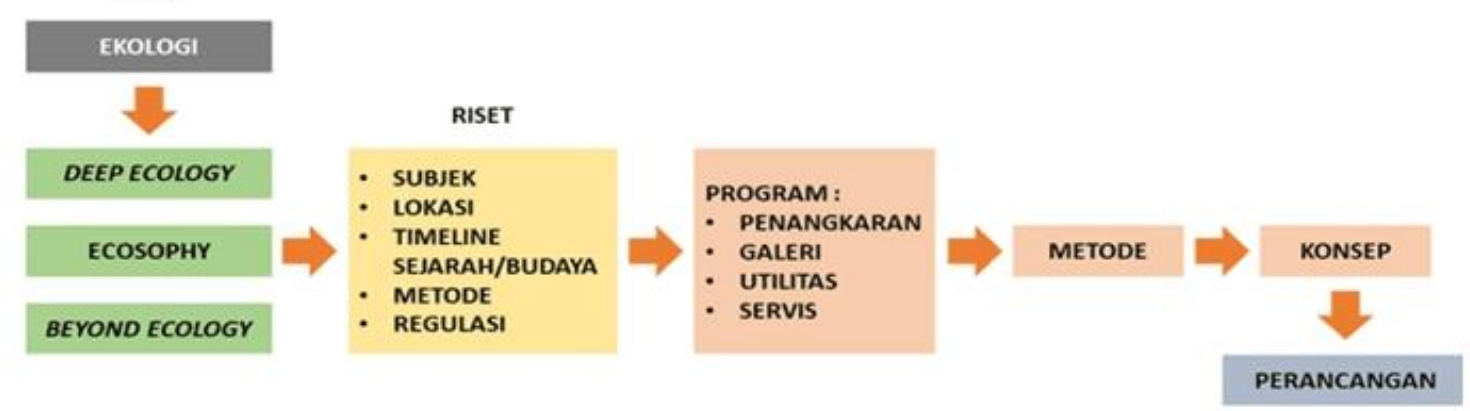

Gambar 4. Alur Metode Penelitian

Sumber: Dokumen Pribadi, 2021

Dari alur metode penelitian diatas dapat dilihat bahwa proses dimulai dari tahap literatur di mana pengumpulan kajian teori berkaitan dengan tema "Melampaui Ekologi". Kemudian dilakukan riset terhadap hal-hal yang berkaitan dengan subjek proyek yaitu burung walet, dengan menganalisis kehidupan walet itu sendiri, lalu habitat walet yang akan difokuskan yakni Karst Ciampea, sejarah dan budaya sekitar tapak yang berkaitan dengan walet, metode yang biasa digunakan oleh orang-orang yang melakukan budidaya walet, baik proses menangkar walet secara efektif dan tahapan memanggil walet serta regulasi setempat yang mendukung proyek perancangan. Kemudian dari riset tersebut, ditentukan program perancangan berikut metode yang digunakan dalam desain dan konsep secara keseluruhan. Sehingga menghasilkan suatu perancangan yang berkesinambungan.

\section{Metode Penangkaran}

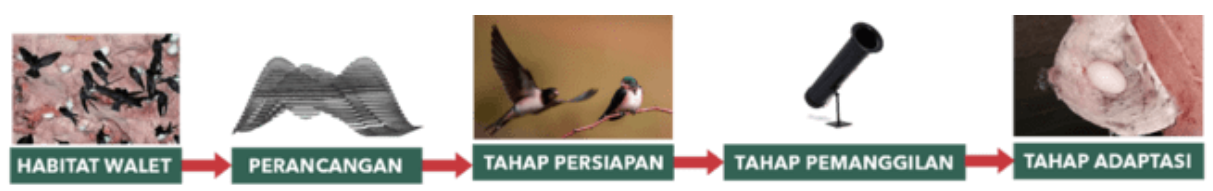

Gambar 5. Alur Metode Rearing Swallow Habitat

Sumber: Dokumen Pribadi, 2021

Proses penangkaran walet dimulai dari analisis bentuk penangkaran yang paling sesuai dengan sifat gerakan terbang burung pada umumnya. Metode ini dihasilkan berdasarkan riset yang dilakukan setelah menentukan subjek proyek. Kemudian ditemukan tipologi ideal untuk 
penangkaran hewan yang terbang yaitu bentuk dome. Bentuk dome sendiri memiliki kelebihan dibanding dengan bentuk lain yang menghasilkan sudut-sudut kaku, karena bentuknya yang melengkung tidak membatasi gerakan terbang burung terutama walet. Lalu proses perancangan dibuat agar menyesuaikan suhu, kelembaban, intensitas cahaya, dan sebagainya yang cocok untuk walet.

Pada tahap persiapan, walet tidak dapat langsung tinggal di dalam penangkaran buatan. Maka dari itu, penangkaran terlebih dahulu ditinggali oleh burung seriti. Kemudian pengelola penangkaran yang mengambil telur-telur walet di gua Karst Ciampea memindahkannya ke dalam penangkaran buatan, untuk diletakkan di nesting room. Kemudian seriti akan mengasuh walet, sehingga begitu walet menetas, akan ada kehidupan baru secara alami di penangkaran walet tersebut. Populasi seriti akan tergantikan secara alami oleh kehadiran walet di dalam nesting room.
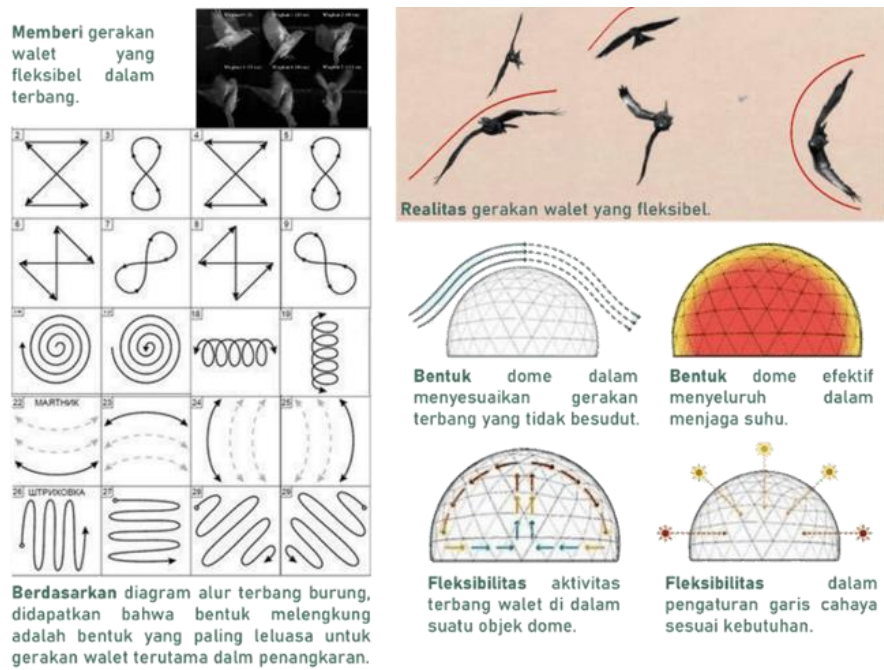

Gambar 6. Metode Swallow Manuever

Sumber: Dokumen Pribadi, 2021

\section{DISKUSI DAN HASIL}

Penentuan lokasi tapak untuk perancangan disesuaikan dengan area yang dilalui oleh jalur walet. Hal ini dapat terlihat karena arah terbang walet dari gua kapur yang berada di sebelah timur karst menuju ke sebelah barat Karst Ciampea yang terdapat banyak vegetasi untuk walet mencari makan.

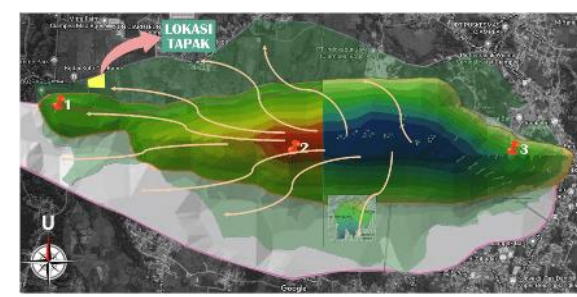

INDEKS PERSEBARAN GUA DAN MATA AIR
$\begin{array}{llll}\text { 1. Gua Pacet } & \text { 8. Gua Sigajah } & \text { 15. Gua Sigodawang } & \text { INDEKS GUNUNG } \\ \text { 2. Gua Pacet 2 } & \text { 9. Gua Sipanjang } & \text { 16. Gua Sidempet } & \text { 1. Gunung Tatarsunda } \\ \text { 3. Gua Vertikal } & \text { 10. Gua Siorai } & \text { 17. Gua Sibesi 1 } & \text { 2. Gunung Ciampea } \\ \text { 4. Gua Sigeulis } & \text { 11. Gua YK } & \text { 18. Gua Sibesi } 2 & \\ \text { 5. Gua Sinema } & \text { 12. Gua Dua } & \text { 19. Gua Siwandra } & \\ \text { 6. Gua Sipeso } & \text { 13. Gua Siwulung } & \text { 20. Gua Tiga } & \\ \text { 7. Gua Simushola } & \text { 14. Gua Sitilu } & \text { 21. Mata Air Cipanas }\end{array}$

Gambar 7. Peta Jalur Terbang Walet Sumber: Dokumen Pribadi, 2021 
Berdasarkan analisis pada tapak, lokasi ini cocok untuk habitat hewan endemik dan sesuai dengan peruntukan lahannya yang terdiri dan di kelilingi oleh banyak vegetasi. Area permukiman penduduk cukup jauh dengan area tapak sehingga nantinya burung walet lebih nyaman terhadap lingkungan habitat penggantinya. Meskipun di sekitar tapak terdapat area untuk kegiatan masyarakat setempat, tetapi bising burung walet tidak akan mengganggu karena terhalang oleh pohon-pohon perkebunan dan tebing Ciampea.

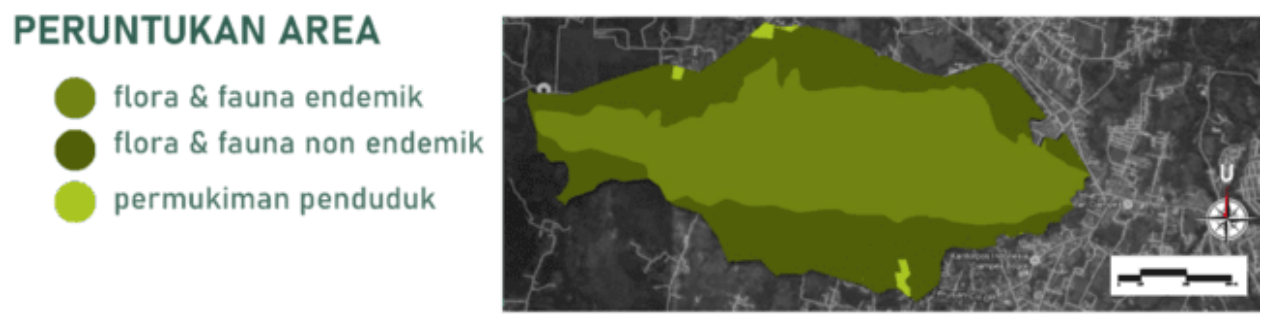

Gambar 8. Pemetaan Peruntukan Area di Karst Ciampea Sumber: Noviana, 2010

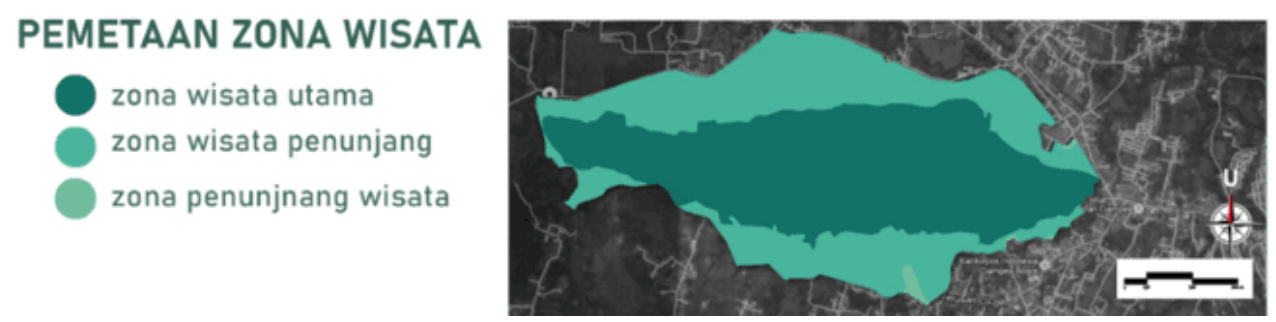

Gambar 9. Pemetaan Zona Wisata di Karst Ciampea Sumber: Noviana, 2010

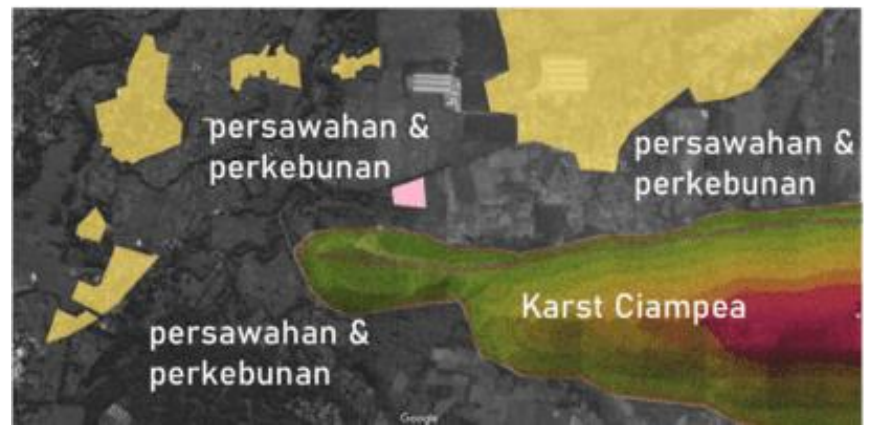

\section{SEKITAR TAPAK}

lokasi tapak

permukiman penduduk

vegetasi

Pertanian dan perkebunan merupakan sumber mata pencaharian utama di Desa Ciaruteun Ilir,

Gambar 10. Kondisi Sekitar Tapak

Sumber: Dokumen Pribadi, 2021

Kemudian zoning dilakukan secara eksperimental setelah melakukan riset terhadap tapak terpilih di kawasan Karst Ciampea. Namun, peletakan massa tetap memerhatikan pemisahan area yang dapat dikunjungi oleh publik, pengelola maupun servis. Berikut ini adalah zoning gubahan dari lantai 1 hingga lantai 3.

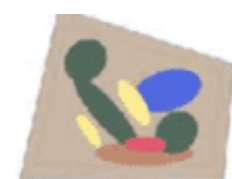

LANTAI DASAR

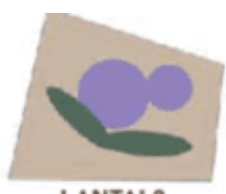

LANTAI 2

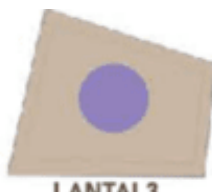

LANTAI 3

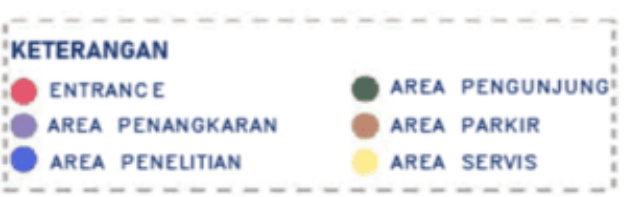

- area penelitian AREA SERVIS

Gambar 11. Zoning Area Program Bangunan

Sumber: Dokumen Pribadi, 2021 
Setelah melakukan zoning eksperimental pada tapak, maka dibentuk suatu transformasi massa. Peletakan massa juga berpusat pada satu titik pusat di bagian bangunan penangkaran di tengah tapak, lalu ditarik garis dengan geometri sekitarnya yang bervariasi, namun tetap menggunakan unsur-unsur lengkung. Berikut ini adalah konsep gubahan massa berdasarkan metode desain dari bentuk gerakan terbang walet.

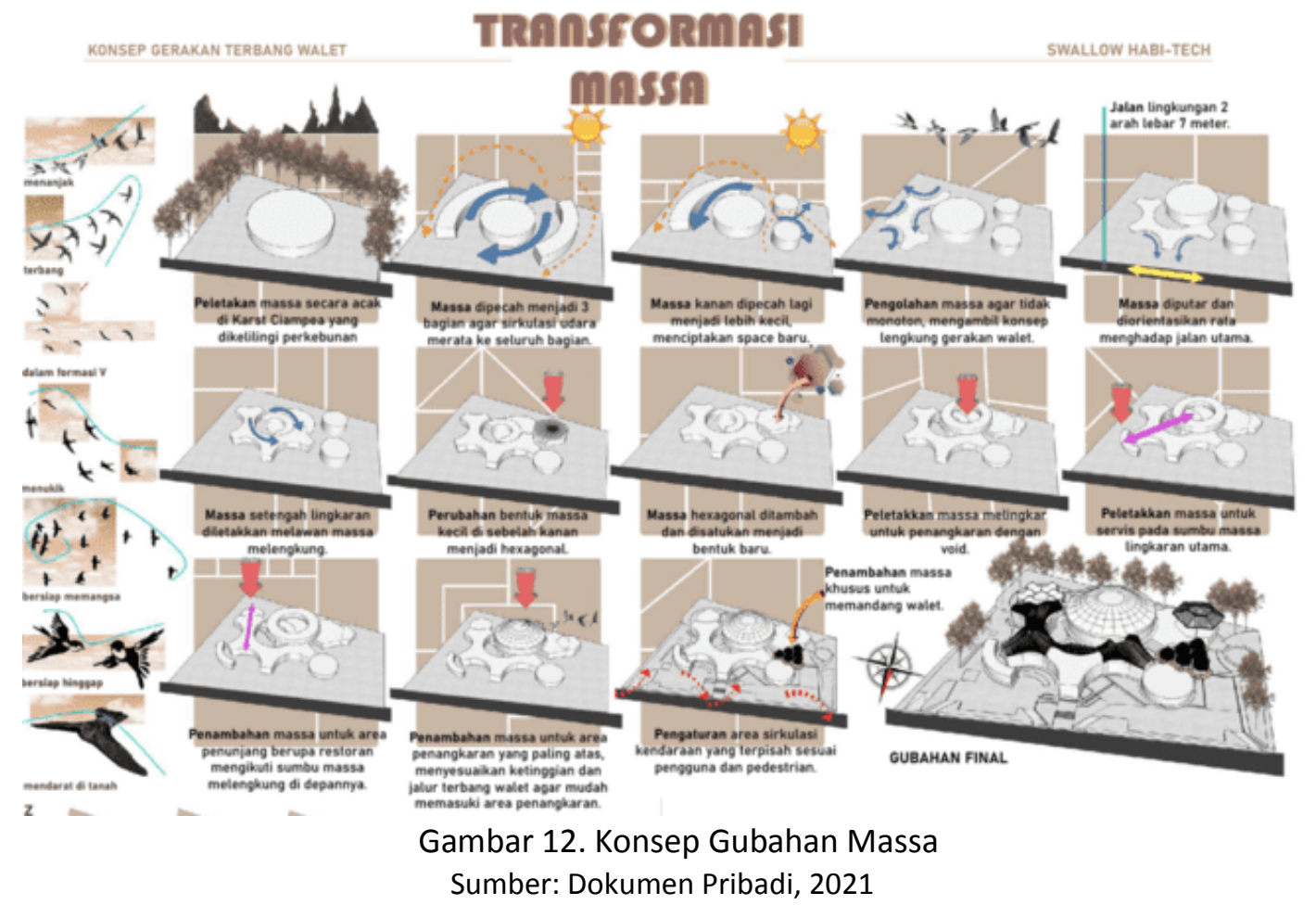

Bangunan memiliki konsep Swallow Habi-Tech dengan mengkombinasikan bentuk-bentuk modern dalam proses desain dengan bantuan teknologi sehingga menghasilkan bentukan yang unik dan menyerupai gua-gua kapur di sekitar tapak. Bangunan terbagi menjadi 3 lantai. Pada lantai dasar dan lantai 2, difokuskan untuk area publik untuk retail, galeri, penelitan pengelola dan utilitas. Disediakan juga penunjang berupa beberapa area pengamatan burung walet yang cukup tersembunyi sehingga terpisah dari aktivitas burung walet secara langsung. Pada lantai 3, difokuskan untuk penangkaran walet itu sendiri. Berupa beberapa area menonjol yang menarik perhatian burung walet dengan berbagai ketinggian. Terdapat void yang terhubung dengan kolam untuk penampungan kotoran walet sehingga bisa langsung dimanfaatkan dan diolah sebagai pupuk dan dapat dijual.

Pada area nesting room walet, peletakan ruangan berada di lantai teratas yaitu lantai 3, karena menyesuaikan dengan ketinggian terbang walet berdasarkan pemaparan aktivitas walet pada kajian teori. Terdapat juga lubang masuk walet di bagian paling atas yang berukuran $40 \mathrm{~cm} \times 80$ $\mathrm{cm}$ sebagai jalur masuk walet. Ukuran tersebut juga berdasarkan riset pada bangunan walet pada umumnya. Pengaturan ruangan pada nesting room dibuat bersekat agar tidak menimbulkan kesan luas dan membuat pengelola juga mudah membersihkan sarang walet setelah ditinggali oleh seriti, sebelum akhirnya digantikan oleh kehidupan walet yang diasuh oleh seriti berdasarkan metode penangkaran.

Dimensi estetik untuk program galeri tercipta sebagai sarana terciptanya suatu persepsi spasial terhadap ruang yang menentang pemahaman antroposentris manusia dari keinginan untuk 
dapat mempelajari dan mengenal kehidupan walet lebih dekat. Maka dari itu, dibentuklah 3 galeri yang masing-masing menerapkan teknologi berbeda.

\section{Galeri See Through}

Galeri ini berada tepat di bawah area penangkaran walet. Pengunjung dapat memandang kehidupan walet, merasakan bahwa walet adalah subjek utama pada proyek. Teknologi yang digunakan adalah material kaca film agar walet tidak terganggu dengan keberadaan manusia di bawah yang memandang mereka, sementara manusia bisa melihat walet.
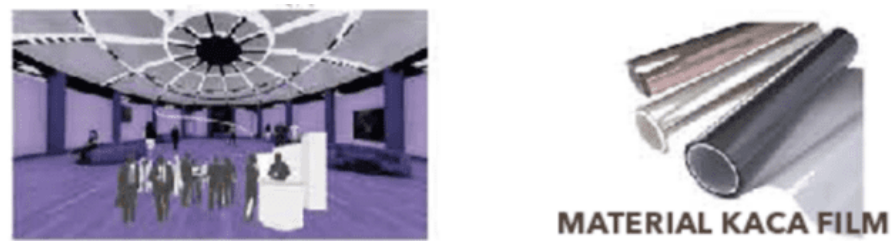

Gambar 13. Galeri See Through

Sumber: Dokumen Pribadi, 2021

\section{Galeri Immerse Cave}

Menggunakan konsep biomimikri untuk meniru bentuk di dalam gua kapur Karst Ciampea. Dikombinasikan dengan teknologi suara di mana pengunjung hanya bisa menemukan jalan keluar dengan bantuan indra pendengaran seperti kemampuan ekolokasi walet.
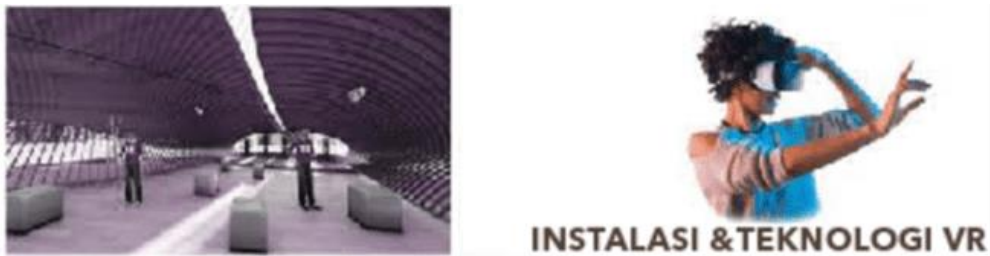

Gambar 14. Galeri Immerse Cave Sumber: Dokumen Pribadi, 2021

Galeri Biosonar

Berbentuk labirin yang dibuat gelap. Pengunjung diajak merasakan langsung pengalaman ekolokasi dengan mengikuti arah suara datang yang dipasang di lorong-lorong labirin untuk dapat menemukan jalan keluar.
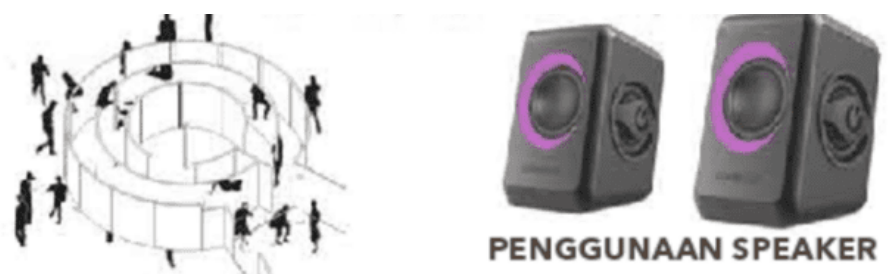

Gambar 15. Galeri Biosonar

Sumber: Dokumen Pribadi, 2021

Pada potongan 3D bangunan dapat terlihat bahwa struktur dominan atap pada area penangkaran menggunakan rangka kremona. Di bagian tengah bangunan juga terdapat rangka indoor yang menjadi pembatas antara galeri See Through dan area penangkaran walet di atasnya. 


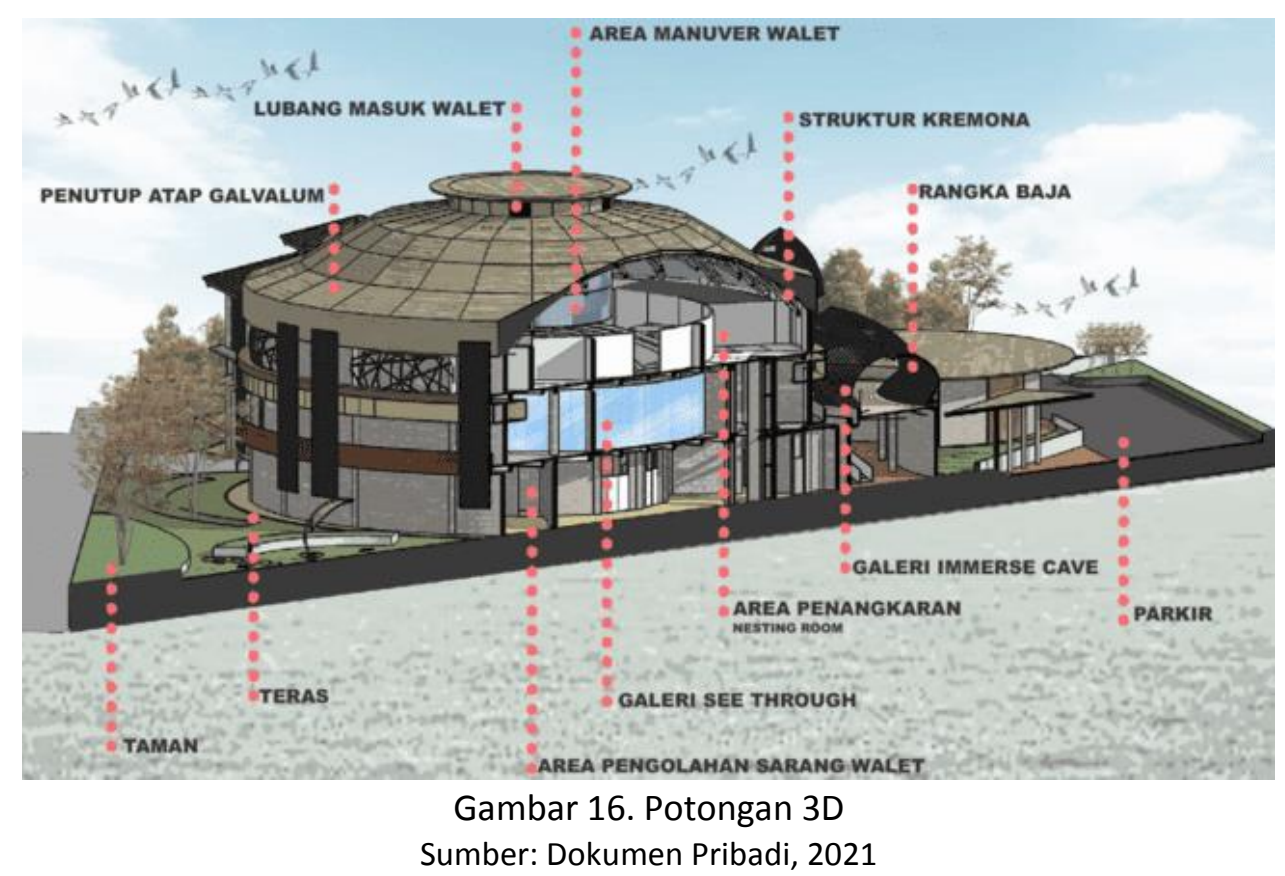

Proyek Swallow Habi-Tech menggunakan kombinasi struktur pada setiap massa bangunan. Massa utama penangkaran menggunakan struktur atap kremona pada bagian paling atas, di mana pada bagian tengahnya terdapat area manuver untuk burung walet masuk dan terbang. Lalu dibawahnya ada struktur atap indoor yang dilapisi kaca film. Fungsinya agar pengunjung pada area lantai 2 yaitu galeri See Through dapat memandang walet yang berada di atasnya. Kaca film sendiri merupakan pelapis agar hanya manusia yang bisa pengunjung yang bisa memandang ke atas, sementara walet tidak terganggu dengan kehadiran manusia di bawahnya. Untuk lebih detail dapat dilihat pada gambar aksonometri struktur berikut :

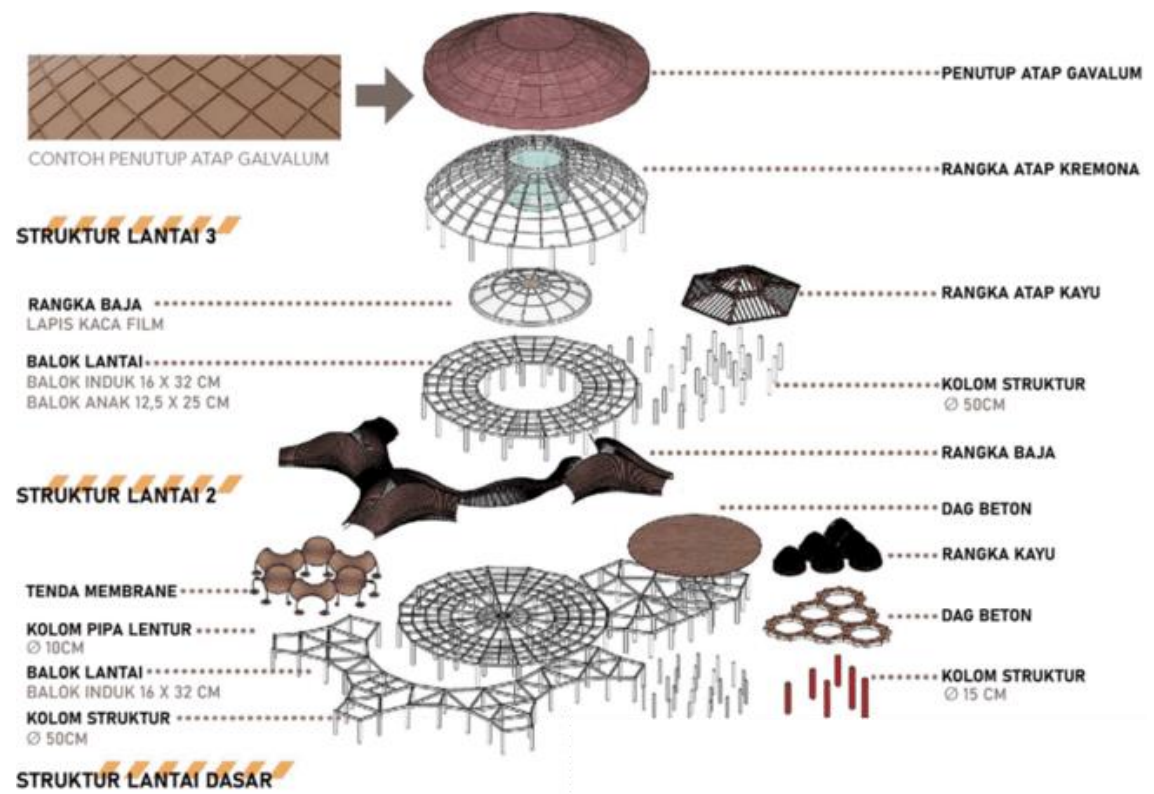

Gambar 17. Aksonometri Struktur

Sumber: Dokumen Pribadi, 2021 
Kemudian, terdapat sistem mekanikal pada bangunan untuk sirkulasi antar lantai dengan bantuan tangga dan lift khusus untuk pengunjung. Tangga menurut penggunanya terbagi menjadi 2 , yaitu tangga untuk pengunjung dan tangga khusus untuk pengelola dan peneliti.

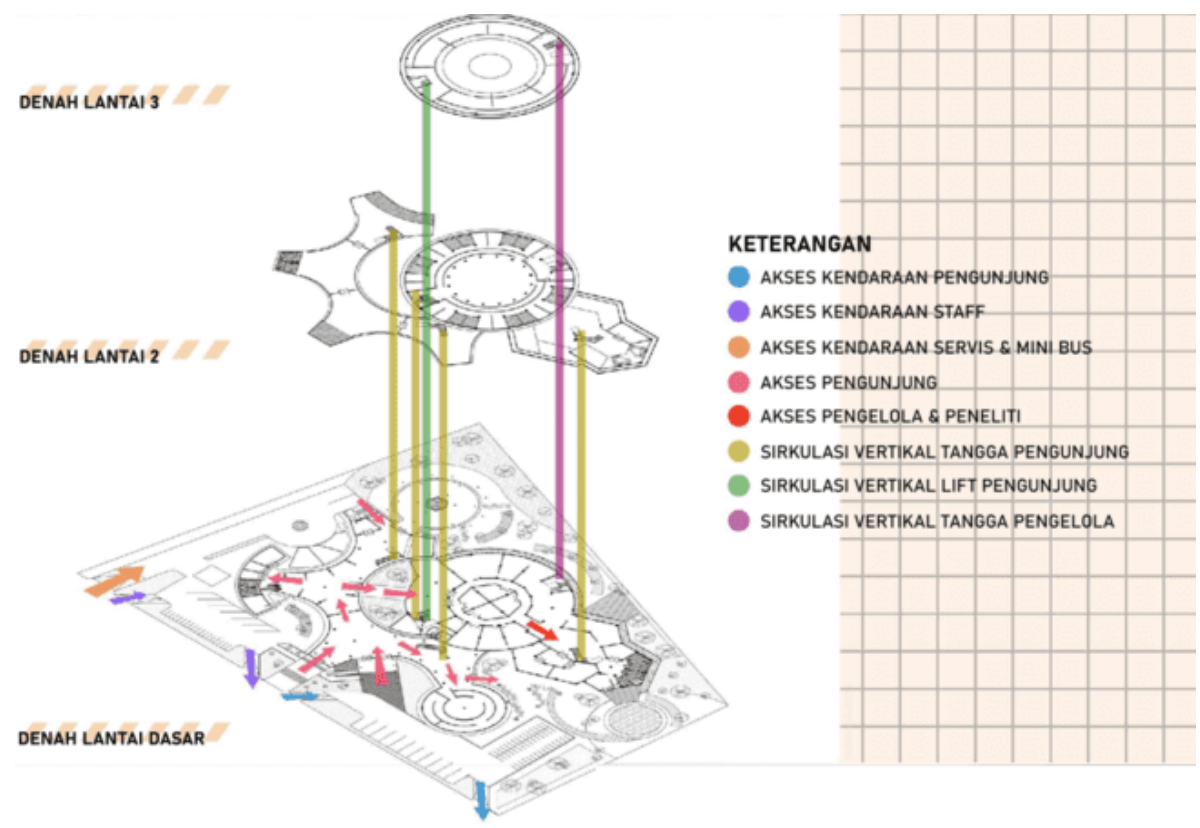

Gambar 18. Sirkulasi pada Bangunan

Sumber: Dokumen Pribadi, 2021

Untuk sumber listrik berasal dari PLN dan genset bangunan. Lalu listrik dialirkan ke trafo dan panel utama, untuk selanjutnya di distribusikan per lantai dengan panel distribusi menuju ruangruang pada seluruh lantai bangunan.

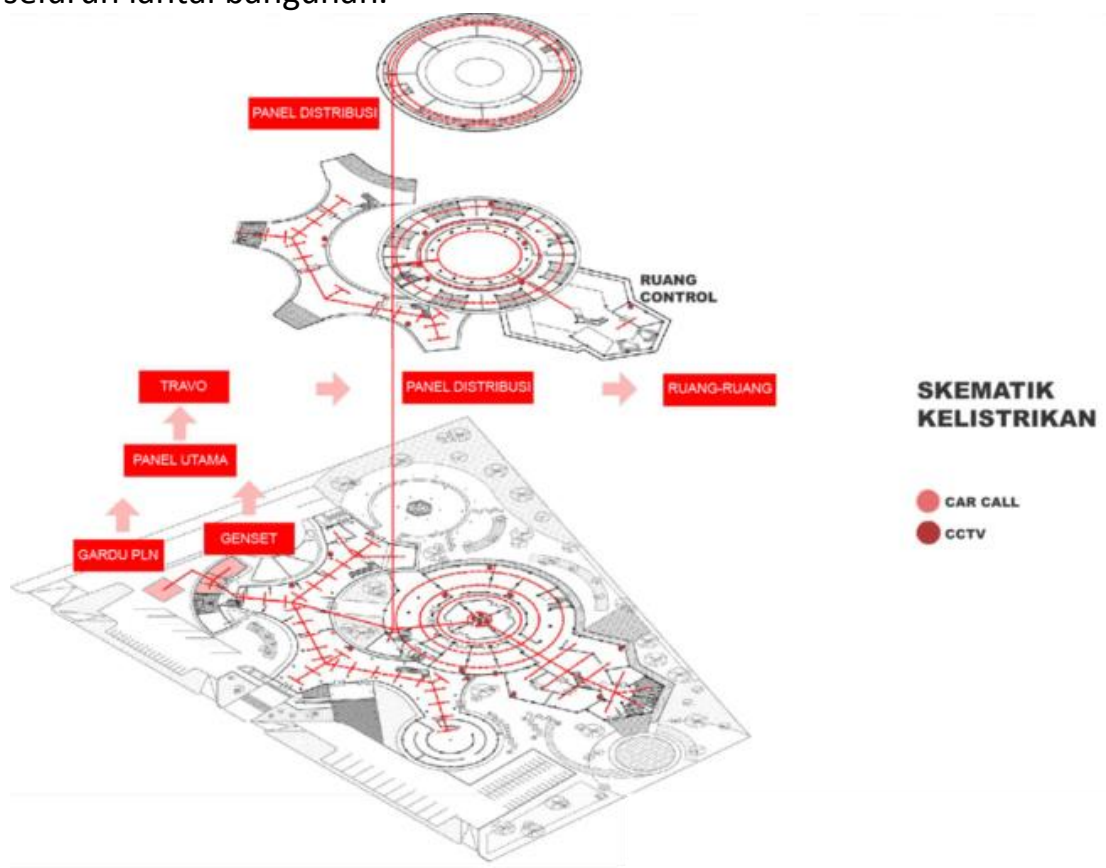

Gambar 19. Skematik Kelistrikan Sumber: Dokumen Pribadi, 2021 
Sumber air berasal dari sumur dan PAM. Keduanya dikombinasikan sesuai kebutuhan. Pada area penangkaran, air untuk kolam walet dipompa dengan sistem down feed ke reservoir atas untuk kemudian di alirkan ke masing-masing kolam. Lalu air pada kolam penampungan kotoran walet bersifat statis, namun ketika dirasa sudah cukup menampung kotoran dengan batas tertentu, maka akan secara otomatis dialirkan ke ruang pengolahan kotoran walet di lantai dasar, melalui pipa-pipa secara dinamis.

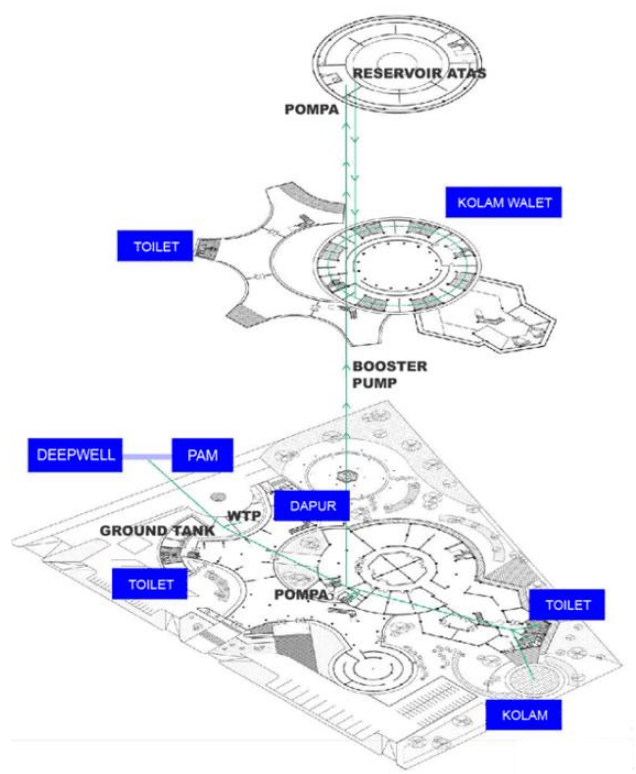

Gambar 20. Skematik Air Bersih

Sumber: Dokumen Pribadi, 2021

Air yang telah digunakan pada bangunan, terbagi menjadi air bekas dan air kotor. Air bekas dapat diolah di WTP menjadi air yang bisa digunakan kembali sebagai penyiram tanaman ataupun untuk penyiram di toilet. Sedangkan air kotor langsung menuju bio septik sebelum dialirkan ke riol kota.

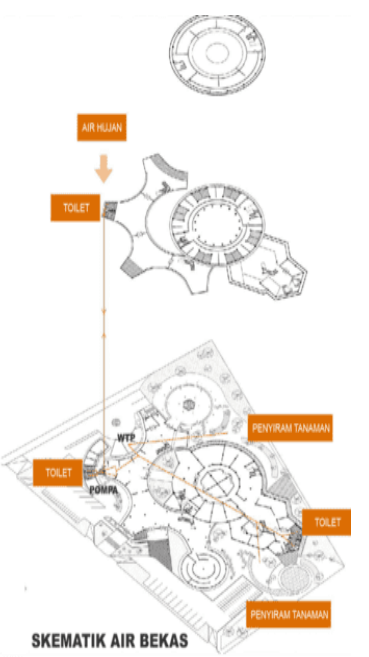

SKEMATIK AIR BERSIH

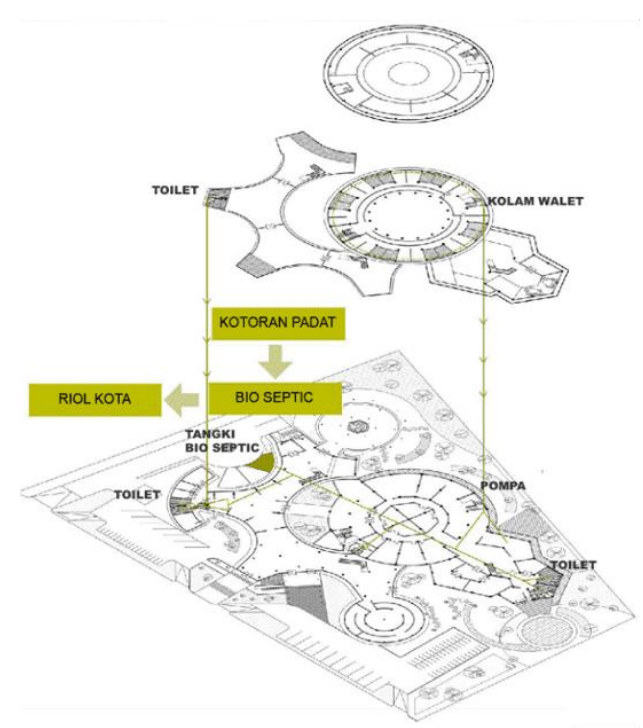

Gambar 21. Skematik Air Bekas dan Air Kotor Sumber: Dokumen Pribadi, 2021 
Sistem pencegahan bahaya kebakaran pada bangunan menggunakan sistem pendeteksi asap dan beberapa peletakan pemadam api manual pada beberapa titik bangunan.

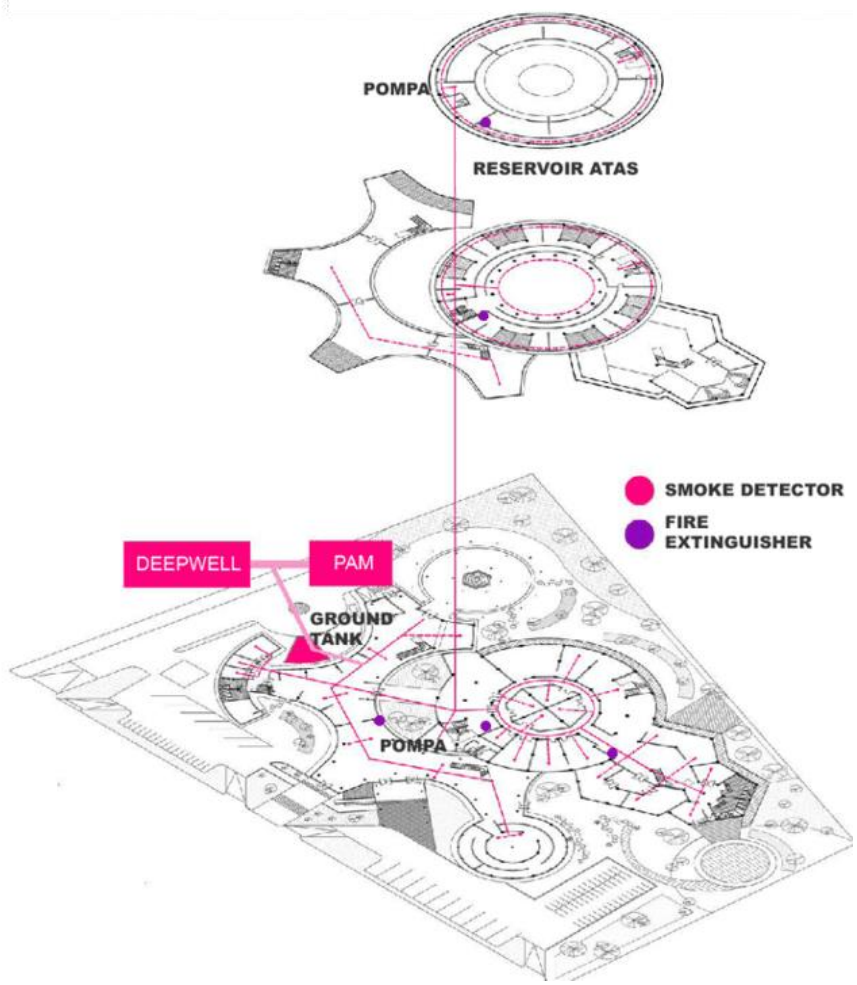

Gambar 22. Skematik Pencegahan Kebakaran

Sumber: Dokumen Pribadi, 2021

\section{KESIMPULAN DAN SARAN}

\section{Kesimpulan}

Konsep "Melampaui Ekologi Menuju Kehidupan untuk Kebaikan dan Kehidupan" dalam arsitektur berkelanjutan untuk membantu menjaga keseimbangan ekosistem burung walet di Karst Ciampea yaitu berupa walet yang menjadi subjek utama perancangan proyek. Proyek perancangan mengacu aktivitas kehidupan walet, mulai dari program penangkaran dan galeri untuk manusia memandang walet sebagai subjek, lalu gubahan massa yang mengambil ide dari gerakan terbang walet dalam aktivitas sehari-hari. Pada akhirnya, penerapan tema "Melampaui Ekologi" pada bangunan ini adalah kondisi di mana antroposentris dipatahkan dengan hadirnya 3 buah galeri interaktif atau ruang spasial bagi pengunjung yaitu, galeri See Through, galeri Immerse Cave dan galeri Biosonar untuk dapat merasakan kehidupan walet baik langsung maupun tidak langsung, tanpa mengganggu walet yang berada di bagian lantai teratas bangunan.

\section{Saran}

Metode perancangan pada proyek Swallow Habi-Tech sebaiknya dilakukan dengan cara observasi langsung ke tapak dan kawasan sekitarnya, untuk memastikan secara langsung kehidupan walet di sekitar lokasi tapak terpilih terhadap ide perancangan. Pengaturan sistem utilitas secara otomatis dapat ditingkatkan sesuai dengan teknologi terbaru untuk memudahkan proses pengolahan limbah walet. Selain itu, pemantauan pada serangga yang mengganggu aktivitas walet secara berkala terhadap area penangkaran perlu diperhatikan agar walet nyaman tinggal di habitat buatan tersebut. 


\section{REFERENSI}

Devall, B. (1985). Deep Ecology. Layton, Utah 8401: Gibbs M. Smith, Inc.

Harris, C. M. (2006). Dictionary of Architecture and Construction. New York: McGraw-Hill.

inibaru.id. (2021), Maret 9. Retrieved Juni 30, 2021, from Inibaru: https://inibaru.id/indohayati/walet-putih-burung-penyuka-kebersihan

Naess, A. (1989). Ecology, Community, and Lifestyle : Outline of an Ecosophy. Cambridge. New York: Cambridge University Press.

Noviana, P. (2010). Perencanaan Lanskap Gunung Kapur Cibadak Ciampea Bogor Sebagai Kawasan Wisata Terpadu. Bogor: IPB (Bogor Agricultural University).

Peraturan Menteri Kehutanan No. P.19/ Menhut-II / 2005 tentang Penangkaran Tumbuhan dan Satwa Liar.

Sessions, G. (1985). Deep Ecology. Layton: Gibbs M. Smith, Inc.

Sumiati. (1998). Habitat Burung Walet dan Seriti di Dalam Rumah di Kecamatan Taronggong Kabupaten Garut. Skripsi Fakultas Hutan IPB. Bogor.

Sutanto, A. (2020). Peta Metode Desain. Jakarta.

Yamin, P., \& Paimin, B. F. (2002). Membangun Rumah Walet Bintang Lima. Jakarta: Penebar Swadaya. 